\title{
The Value of the University Armed Service Units to the Armed Forces
}

In this chapter, we draw on interviews conducted with unit COs to explore the value of the USUs to the armed forces, from the perspective of those charged with unit leadership and management. The interview schedule used for these interviews is provided in Appendix 3. Note that in this chapter, we focus on those parts of the interviews which discussed the question of value in terms of the USU-university relationship. The interviews with COs also included a large number of questions about the value of the USU experience to student participants. We have not included analysis of responses to those questions here, because there was nothing in $\mathrm{CO}$ responses which diverged from the accounts given by students and graduates and detailed in full in Chapters 3 and 4. Unit COs were asked questions in interviews about the value of the USUs to students with no prior knowledge of the results of the student survey or the graduate interviews, and it is notable therefore that COs discussed exactly the same points as were raised in the survey and graduate interviews. We do not elaborate on these points here, but would emphasise that omission here is not indicative of lack of understanding and awareness amongst COs but rather of a desire to avoid repetition. The correspondence between student, graduate and $\mathrm{CO}$ views on value was striking.

\subsection{The commanding officers}

A total of 15 commanding officers were interviewed for this research, five each from the OTC, UAS and URNU, in five different geographical locations around

How to cite this book chapter:

Woodward, R, Jenkings, K N and Williams, A J. 2015. The Value of the University Armed Service Units. Pp. 139-154. London: Ubiquity Press. DOI: http://dx.doi. org/10.5334/baq.e. License: CC-BY 4.0. 
the UK. The sampling strategy was not determined by a need for representativeness across the 46 units, but rather by a need to explore the experience of command in different localities, and to capture something of the differences and similarities between service units in locations which engage with universities of very different types. Further information on the methodology used to define the sample and conduct the interviews is given in Chapter 2.

\subsubsection{Postings and experience}

OTC and URNU COs stated that their postings were of two and half years' duration, with the UAS postings rather shorter (up to two years). We interviewed COs whose period in command to date ranged from two months to just over three years. One $\mathrm{CO}$ had had a previous appointment to a USU before the present one, and one had experience as a commissioned officer and staff member whilst at university (rather than as a student member of a USU). All the OTC COs had attended a university, and of these five, three had been OTC members. Two UAS COs had been to university, and one had UAS experience. Four of the five URNU COs had graduated from university (and the fifth had left his degree programme in his first year to join the Royal Navy). Four of the URNU COs had no prior experience of the URNU, and one had had a reserve place in an UNRU in his final year of study once he had been selected to join the Royal Navy on graduation. Two of the COs were women and 13 were men.

The 15 COs had, between them, tremendously varied careers in their respective armed forces to date. Two of the OTC COs were reservists so had combined civilian careers with work in the British Army (including operational deployments). All the UAS COs were qualified flying instructors with jet or other pilot experience. All the URNU COs were navigation qualified.

All three parent services had pre-requisites for CO selection. For the OTC, the $\mathrm{CO}$ post is classed as a command tour. All five COs interviewed had slightly different understandings of both the Army's rationale for selecting them to that post, and their own rationale for wanting to take up the command (and note that all were familiar with the OTC themselves prior to their posting). One of the Reserves members had expressed an interest in the post, both because he was familiar with the OTC and because he was a reservist and thus in civilian employment with limited personal mobility. One CO considered that his previous Army career in a range of varied and significant roles meant that he was considered to bring something quite specific to the role ('you want someone who has done something'). Two COs had personal connections with the cities (and in one case, the local university) to which they were posted. Two of the COs noted how keen they had been to take up the CO post, one because 'I knew I would have a really good time, because you're dealing with young people who are enthusiastic', the other because under a previous post he'd been so impressed by the junior officers under his command ('they changed my view very much 
of the educated youth of today') and how 'phenomenally good' many of them were. The UAS COs cited their enthusiasm for their flying instructor roles. One cited parental responsibilities which were seen as compatible with the posting. Two talked of the appeal of the post because of the autonomy and responsibility they would have and the challenge of this (and one talked of turning down what was seen as a more prestigious posting as a squadron flight commander to take up the UAS posting). One mentioned how another RAF colleague had urged him to take up a UAS command post were one to become available, because it was deemed both challenging and enjoyable. The URNU COs all mentioned how the post, because it was a command post requiring command qualification to take charge of the P2000 ships, was a good career move. Two mentioned explicitly how hard they had worked to get that command, and one spoke of what a privilege it was to be in command of an URNU.

Three issues emerged during the interviews regarding $\mathrm{CO}$ placements. The first was a question about the length of the $\mathrm{CO}$ posting. The time period accorded with standard lengths of time for postings within each of the three armed forces, but the question was raised about whether, given the nature of the $\mathrm{CO}$ role and the significance of relationship-building in that role within the host universities and the wider locality (particularly with business), the two and half year average posting was sufficient. The second issue was RAF-specific and concerned the lack of sufficient numbers of suitably qualified applicants for the $\mathrm{CO}$ role, given that it required a flying instructor qualification (something felt to be essential in the role) and the relative lack of qualified applicants. The third issue was URNU-specific and related to a shift initiated in 2014 by which URNU command was de-linked to P2000 command. Previously, URNU commanders had had responsibility both for the unit and for the ship. The Royal Navy instigated a change splitting this role between two posts. All the URNU commanders indicated that they saw this as a positive development, not least because it expanded the range of command opportunities within the Royal Navy, and also because it would enable other specialist areas in the Royal Navy to become involved with URNU (and not just those who were qualified to command a Royal Navy vessel).

\subsubsection{Commanding Officer remits}

It was clear talking to the COs that their remits encompassed formally defined responsibilities, but also that individuals had the opportunity should they wish to undertake a variety of additional activities; the remit was therefore often much 'broader than people realise'.

COs had responsibility to deliver a training syllabus, determined centrally by, respectively, Royal Military Academy Sandhurst (for the OTC), RAF College Cranwell (for the UAS) and Britannia Royal Naval College (for the UNRU). COs had command of staff working under them in their unit in the delivery of 
that training, which included military-specific and other (for example, adventurous training) activities. Their responsibilities included oversight of training for that staff, who comprised both Regular and Reserves personnel in many cases. The COs were adamant that the priority for students was to complete their education and graduate with a degree, and that this was the fundamental context to their delivery of the training syllabus and management of the unit.

For the OTC and UAS, although not for the URNU, there was a far greater emphasis on the potential use of the USU as a mechanism for recruitment. This included providing practical assistance with applications (for example, writing reports on students applying for selection with the Regular and Reserve armed forces), and a more general process of gauging the interest of potential applicants in an armed forces career and offering guidance where appropriate. COs could assist with the management of an application to join the armed forces, and there was awareness that this might also involve engagement with parents. Although the URNU places far less emphasis on recruitment as a core part of its mission, the assistance URNU COs could provide to students considering Royal Navy participation was of course recognised.

Unit COs recognised that they were ambassadors for the armed forces in terms of wider civilian engagement. They might be influential on individuals who would go on to achieve positions of leadership and responsibility in later life (where having a positive attitude towards the armed forces might, in due course but in unpredictable ways, be positive for the armed forces). They could also be significant within universities by showing the presence of the armed forces. This was primarily through channels facilitated by the MEC, but not exclusively.

A key point made by some COs was that they had considerable capacity for autonomy in determining how best to work to achieve the requirements of the job ('mission command', as an OTC CO put it). They could use their own judgement to determine how exactly specific parts of the unit remit would be delivered (within an established framework). This had been noted as one of the attractions of the job. Having the capacity to do this was also felt to be beneficial; for example, one $\mathrm{CO}$ talked of how significant he thought wider public engagement activities were for his unit, despite not being explicitly stipulated in his remit, and another gave an example of engagement in university debates on defence issues as evidence for wider engagement.

\subsection{The university armed service units and the universities}

COs had many, very interesting things to say about the military-university relationship, significant both for the specific details provided enabling a picture to be built up about how that relationship functions, and also for the wider issues this picture then raises for the question about the value of the USUs underpinning this book. It was clear that the military-university relationship went a 
considerable way beyond the simple fact that students registered at one or more universities will also attend an OTC, UAS or URNU in the region and work under the command of that $\mathrm{CO}$.

\subsubsection{University armed service units and their catchment universities}

All the USUs draw students from more than one university, and one CO in the sample had a particularly large catchment from a federal university. It was clear that the specificities of each university, in terms of institutional origins, its positioning in the national market for undergraduates under the fees regime and more internationally in the global higher education system, the types and range of degree programmes on offer, a university's research reputation, its current or past patterns of UK student recruitment (nationally or locally) and a university's physical location in relation to the unit (thus shaping the ease of student engagement) were all factors shaping the military-university relationship. Also mentioned were universities' existing links and past traditions of engagement either with military forces or one of the branches of the UK armed forces within the locality, which might be influential on the USU-university relationship. For example, one university located in a city with centuries of marine industrial involvement seemed determined to maintain strong and visible links with its local URNU. Universities were perceived as exhibiting a range of views along a continuum from support to antipathy towards the armed forces. However, on probing it was clear that it was Student Unions which were the issue rather than the institutions themselves (and we consider this issue in more detail in section 5.2.3. below).

All the COs had much to say about the differences between the universities within their catchment area, which translated into often quite marked differential levels of recruitment from different institutions. It was partly a question of geographical proximity and distance, reflecting historic patterns of USU basing and the considerable longevity of some units, particularly amongst the OTCs. This meant that it was, quite simply, much easier for some students to attend weekly drill nights than others, depending on their place of education. Some units provided assistance with transport in recognition of the challenges of distance (particularly for UAS members). Differential levels of recruitment also reflected the nature of the universities in a catchment: as a rule, the more established, research-intensive Russell Group universities had greater levels of involvement, and although that dominance was receding it was still notable. A number of COs talked at length about why certain recruitment patterns persisted, and what they as COs could and could not do to shape these. We encountered no comments which suggested that the students in certain universities were somehow seen by COs as unsuitable or unsuited to USU participation; indeed, the point was made that it was students in the newer or smaller specialist universities who potentially had the most to gain from USU participation, in terms of the individual benefits and value-added of the experience. This was 
thought to be a reflection of the socioeconomic background of students attending these institutions, in turn reflecting the fact that these students may not have had access to particular opportunities, for example to adventurous training, which students from more advantaged backgrounds (and attending Russell Group universities) may have had in their pre-university lives.

All the COs reported that although there were differential levels of recruitment to their unit from the various universities in their catchment, the mixing of students from different institutions was beneficial both to the students and to the unit. Some commented that differences between the students, on the basis of university attended, were discernible; for example, a URNU CO noted that he could see differences within the unit between the students from a very prestigious academic institution, a 1960s plate glass university, and a small, new post-1992 institution. The point was not that some students were 'better' than others, but rather that the range and thus mix of student abilities and aptitudes was beneficial both to the unit in operational terms, and socially for the students themselves.

\subsubsection{University armed service units and the Military Education Committees}

There are currently 20 Military Education Committees (see Chapter 1), and they are often part of the formal governance structure of universities, a reflection of the Haldane reforms which established the OTC units in 1908. All the COs attended MEC meetings, which are held two to four times per year, and to which COs provide a report on unit activities.

A range of opinions were expressed about the utility of the MECs for the units, and for the COs. MECs were recognised as a mechanism for USU-university contact, and some COs considered how useful MEC members had been in helping them work their way round and understand a university's systems and practices. Other COs had more critical views on what MECs could provide. Much seemed to depend on the make-up of the MEC. COs noted the significance of the role of the MEC Chair, and the utility of the relationships they were able to cultivate with that individual if he or she had a position of significant influence or responsibility within a university, or had high-level contacts across several universities in a locality. Some COs reported that they had been proactive on arriving in post in developing a relationship with that individual, and they valued the line of communication with the university which that relationship could potentially open up. A number of COs had also developed relationships with academic registrars or equivalent (who may or may not be members of an MEC), because of the significance of the registrar's role with responsibility for student experience.

What was less clear to some COs was the value added by the MECs beyond this. Units are run autonomously from MECs, so MECs had no active input 
into the units. Although they were conduits for communication with the universities within a USU catchment, much depended on the position of an individual representative within their university, for example, whether they were appointed to the MEC because they had administrative authority, or because of a more general interest in military matters. Where MEC members had administrative responsibility at senior level, this was far more effective than those involved with an MEC solely on the basis of past educational or military experience, or just interest in military affairs. Whilst it was recognised that individual members often brought educational and military experience with them, there were questions as to whether this was the right kind of expertise needed. One CO talked very explicitly about what he needed from his MEC: he needed to feel that the university was taking an interest in the USU, and needed an MEC which could help him in terms of opening up opportunities for the unit to show the university what it was and what it could do. An example was given of OTC involvement in a week-long series of events run by one university around innovative learning, where the OTC was able to provide some events with a leadership focus. The $\mathrm{CO}$ concerned felt that this had been a valuable event, not just for the student participants (who by definition were not OTC members) but also for the wider visibility of the unit.

There were questions too about the purpose in the present of a committee established under a very different set of educational and military circumstances, which had differing levels of involvement from participating universities dealing with a broad range of issues across the three service units (and some also include DTOEES representation where a DTUS squadron is present). One unit had established a Liaison Committee to meet its own needs for university liaison, which included one representative from each of the 10 universities in its catchment. The advantage of this was that this group could focus entirely on issues specific to that unit, and that unit's engagement with students in a range of universities in the catchment area.

The relationships which COs reported with university Vice Chancellors varied markedly. Some COs saw their Vice Chancellors as largely uninterested in the work of the units, and some had managed to meet with these individuals directly. The point was made that in the context of large organisations such as universities, USUs are quite small and potentially quite ephemeral to the daily and more strategic business of running a university.

\subsubsection{Relationships with student organisations}

COs reported a range of experiences in their relationships with student organisations, primarily Student Unions. Student Unions exist independently of universities, and are not subject to strategic steer from Vice Chancellors, academic registrars, MECs or individual academics. The relationship with Student Unions is significant for USUs because of the need for units to recruit from 
the student body, particularly at Freshers' Fairs and similar events hosted by Student Unions to enable students (particularly on arrival at university) to join various clubs and societies. Some Student Unions were antagonistic towards the idea of USU involvement at Freshers' Fairs, and COs perceived this as being driven by a (mis)understanding of the role of the units in recruitment to the armed forces to the exclusion of other opportunities that the units offered students. In some cases, this meant that USUs were denied the opportunity to have a stall in the central Freshers' Fair location. ${ }^{64}$ One CO reported that one of his Student Unions had not wanted students and personnel in uniform on the stand, but were happy to host a stand staffed by individuals wearing polo shirts with the unit logo.

COs also raised the question of charges to USUs for participation at Freshers' Fairs. Student Unions can charge organisations for having a stall at an event. Some COs reported that they had been charged a corporate or business rate rather than student society rates, which they thought was unfortunate, given that their mission was focused on student development rather than commercial enterprise. The question was also raised about pressure from headquarters, in view of charges, for units to prioritise representation (particularly if they were being charged corporate rates) at Freshers' Fairs in universities which traditionally had higher rates of USU participation, as a cost-saving measure. In the view of some COs this was misguided because in their experience this might mean differential access to USU participation.

Some COs were quite explicit in identifying certain universities as having a long-standing anti-militarist politics, such that they did not want to see USUs on campus. Student Unions in the newer universities were often identified as more likely to hold this view, although it was often hard, in conversation, to conclude the reasons for this, as many of the newer universities had far less experience with the units and it was unclear whether it was a question of lack of interest, lack of knowledge or explicit resistance to the idea of the units. This was thought to be ironic because, in the opinion of one $\mathrm{CO}$, students attending a new university in his catchment had the most to gain (the most value added) from the USU experience in terms of their skills development and increased employability. We should also emphasise that the issue of antagonism from Student Unions was not universal, and some COs reported no issues at all.

Questions were also raised about how, exactly, engagement with the wider student body could and should be pursued by COs. One CO noted that he

${ }^{64}$ From an alternative source (and not from an interview), we were told an anecdote laden with irony about the consequences of Freshers' Fair organisation. In one university where the Student Union had resisted the presence of the USUs at the Fair, the organisation of the event had been outsourced to a private sector events planning company. This company had in turn responded positively to a request by a local Reserves unit for a stall at the Fair for Reserves recruitment purposes. So Student Union resistance to the USU on the grounds that, in its view, it was a recruiting organisation for the military, had come to nothing. 
had deliberately sought out a meeting with the new Student Union PresidentElect in one of his universities, on the grounds that he thought his role should include engagement with representatives from across the university, including the Student Union, and that personal contact was the best mechanism to achieve this. As with COs themselves, the regular rotation of Student Union presidents and officers was also an issue in relationship building and maintenance. There appeared to be quite a short window of opportunity for COs to make contact with incoming union officers, and this compounded the issue that unions might change over a period of time with regards to their acceptance or otherwise of USU recruitment stalls at Freshers' Fairs. COs were very aware of how they might be perceived on campus. Another $\mathrm{CO}$ discussed an event which had been held for students at one of his catchment universities which, in his view, had ended up portraying the armed forces in a very traditionalist way ('if you had never come across the Army before it might have looked all a bit Ruritanian and quite bizarre') and which had not, in his view, given students a more appropriate view of what the Army, via the USUs, could offer them. COs were also aware that, for the OTC with an increased emphasis in its mission on recruitment to the Regular and Reserve forces, that the 'pitch' units made could easily get caught up in the fallout from current affairs. COs were also very aware of the need for dialogue with student organisations; one CO, for example, questioned why Student Unions were not represented on his local MEC as he could see value in having a student presence at these meetings. ${ }^{65}$

\subsubsection{Informal university armed service unit-university relationships}

The military-university connection also worked in highly informal ways. COs gave examples of being approached by colleagues within the armed forces needing information on a particular topic, which was provided by academics within a CO's university, of being approached to engage in defence debates, and of being asked to assist with the delivery of training packages run through a university business school to a third party. Much seems to depend on the ability (because of competing time commitments) of a CO to undertake such liaison activities, not least undertaking the basic groundwork required to establish and maintain relationships with individuals in an institution. Because universities are often very complex organisations in institutional terms, the development of personal links was thought to be key. It was also recognised that this took time.

${ }^{65}$ This echoes practice adopted in many universities (seen by many as an example of good or best practice), of including student representation at the Boards of Study or equivalent which oversee the management and strategic direction of degree programmes. 
There was also an issue of perception amongst university staff of what, exactly, the units were for. COs recognised how difficult it was to communicate this message to a large number of staff, particularly around the skills training, employability and personal development work that USUs saw themselves as conducting.

\subsection{The value of the university armed service units to universities}

We asked COs for their observations about the value that universities get from their association with a USU. A number of them commented that they were not necessarily the best people to ask (and indeed, we asked this question directly to university representatives - see Chapter 6). All the COs emphasised that there had to be value to universities through the skills, personal development and thus employability of students as graduates. A number of COs were able to provide anecdotes about the effect of unit participation on particular students, in terms of their increased confidence and abilities, and extrapolated from that that there had to be benefit to the universities in terms of the quality of the graduates, who would then become ambassadors for a particular university in later life. One university contributing small numbers was thought to benefit greatly because of the opportunity the unit provided for participation to be accredited as part of the public service-related degree programme. The obvious point, which a number of COs also made, was that the numbers of students who could use the USU experience in this way was actually tiny, relative to the number of students graduating each year from a UK university. Indeed, the proportion was getting smaller over time as units maintained their size and universities (and the higher education sector) expanded. Furthermore, the experience was not open to all students, either because of the nationality qualification (so apart from Commonwealth students, international students were not eligible to join) or the medical and fitness requirements.

COs raised other points about value, from the influence that USU members might have on the attitude of their student peers. Two COs talked of the kudos two of their respective catchment universities were thought to achieve through association with the units (one a UAS in a prestigious university, the other a URNU in a maritime city). Another talked of the public relations work done by the UNRU ships when sailing away from their home ports but visibly representing a particular city or region and its universities. Yet there was significant discussion about whether, in fact, universities understood the units, an honesty about whether in fact the universities did get anything out of the relationship and the fact that the relationship and thus value to universities was subject to change over time. One $\mathrm{CO}$ in particular was adamant that his main recruiting university could do much more to promote his unit, for example by featuring 
it as a recruitment factor for the university in its prospectus and other promotional literature. Another talked about his suspicions that one of his catchment universities (again, a significant source of recruits to his unit) had at best a lack of interest, or more specifically an antipathy towards having visible links with a military organisation. One CO was very frank in his assessment that the higher education sector probably gained relatively little, directly, through the relationship with the USUs. We return to this question in Chapter 6.

Also noted by COs was the value to individual academic researchers in universities of having on hand an identifiable contact within the armed forces who could assist with questions about military issues arising from academic research. We, as authors of this book, recognise this absolutely, having on a great many occasions drawn on our local COs for points of information both about USUs and about wider military issues. We are also aware of other colleagues doing the same, from disciplines as disparate as engineering, food marketing, archaeology and fine art. Several COs mentioned how they had similarly been approached by academics in their catchment universities, and indicated how willing they had been to provide assistance and contacts.

\subsection{The value added to university armed service units and the armed forces from the university relationship}

COs were asked about the value which they thought their USUs gained from the association with universities. Having access to students to participate in the unit was the obvious answer, and these may be high-calibre individuals which the unit would benefit from having, and who might potentially be interested in a career in the British armed forces. But this was also a provocative question because it then raised the issue of what specifically the value might be in a demonstrable link to universities. The units, in other words, could recruit students freely, without needing a relationship to the universities from which students were drawn. A number of COs noted the benefits that accrued for the units through the relationships they were able to foster and engage with via MECs, but this was not universal. The units in some cases recognised that there was value to be had from association with a particular university, if that institution were a prestigious one. One $\mathrm{CO}$ also mentioned access to university estate resources (for example, their sporting facilities).

COs were also asked quite explicitly about the wider benefits the armed forces received from a relationship, via the USUs, with the universities. The key issue here was about the relationships that USUs were able to inculcate with students. These students might enjoy their participation in a unit and develop an understanding of military and defence matters which they would then take with them to the civilian workplace. This was seen, from the perspective of current COs, as particularly significant at a time when the armed forces were contracting, and declining numbers of the civilian population were perceived as 
having knowledge of the armed forces. Alternatively, and crucially, individuals through unit participation could potentially develop (if they did not have this already) an interest in military participation as full-time officers, or part-time through the Reserves. The potential connection with the Reserves was particularly significant in OTC CO minds: as an employer, universities could be the target of armed forces attempts to increase awareness of Reservist opportunities, and USUs had a part to play in that.

The point was also made that the contemporary British armed forces, because of the scale of the reductions through austerity but also reflecting shifts in UK foreign policy and defence missions, was having to learn its place in the world afresh. Part of this process involved establishing new forms of relationship with the civilian world to reflect a new reality, and the USU system was part of that.

\subsection{Commanding Officer perceptions of the value of the university armed service units}

All the COs were asked at the start and the conclusion of their interview to describe what they thought the value of the USUs was, is or could be, and were encouraged to reply in whichever way they wanted. The CO responses provided a great range of explanations on value. These have not been quantified, rather the intention here is to show in narrative form the range of issues that the sample of COs identified as comprising the value of the USUs.

\subsubsection{The value to students as individuals}

The value of the USU experience to students was seen as lying primarily with the skills the USU experience could help students develop, primarily in the form of transferable skills which would enhance employability. These skills included the transferable skills cited in Chapters 3 and 4 by students and by graduates, and we do not repeat them here. The COs, because of their position, articulated how in their view some skills in particular, including the ability to work under pressure, to develop a work ethic, to plan and problem-solve, and to provide leadership, were skills that they thought the armed forces were both seen to develop particularly well through military practice, and which also exported well to the civilian world, particularly the workplace.

Personal development was also thought to be of significant value to individuals, in terms of the self-development and character-building aspect of the USU experience which emerged through a student being taken out of their comfort zone, and in terms of activities which brought increased self-confidence, including activities which might be initially perceived as fun, like adventurous training, but that were not frivolous. Social skills were also seen as being 
developed, including matters of etiquette, and of being able to engage with a range of different people in diverse social situations.

The USU experience was also thought to develop a sense of good citizenship amongst students, in terms of their development of a sense of responsibility, including social responsibility. This might be developed and manifest through charitable work. Students were taught to look out for others as part of their USU training, and this experience was thought to develop an idea of selfless commitment to others.

The social side of the USU experience for students was also recognised. Students made friends and had access to a smaller group within a larger institution which could help with the transition to university life. The USU experience was thought to be fun, and the significance of enabling the USU experience as an enjoyable one was widely recognised by the COs. The units could also provide access to opportunities not otherwise available to an individual, for reasons of cost or for reasons of general availability. Adventurous training and opportunities for overseas travel were key, but also access to quite specific resources, such as flight and maritime navigation training.

\subsubsection{The value to the armed forces}

In contrast to the students and graduates, the COs placed much greater emphasis, when considering the broad question of value, on the value of the USUs to the armed forces. Significance was placed on the visibility of the armed forces which the USUs were thought to enable or enhance, including the utility of being able to draw on USU members to visibly boost the numbers of people in uniform at public events, and the utility of the URNUs in being able to take the P2000 vessels to locations not accessible to larger Royal Navy ships and thus being able to, literally, fly the flag for the Navy. Charity work undertaken by officer cadets was frequently cited as of benefit in terms of increased public awareness and visibility of the units. USUs provided a mechanism for interaction between military and civil society. The units were also beneficial for the armed forces in cases where unit engagement with industry enabled not only the message to be promoted that USU graduates had employability and skills, but that this was a feature of ex-forces personnel as well. The links to universities were part of the value of the USUs in terms of enhanced public visibility, and constituted one particular set of connections amongst many between the armed forces and civilian society, at a time when the multiplicity of those connections was seen to be diminishing.

COs also referred to the argument that the USU experience had longer-term benefits for the armed forces through the passage of USU graduates into the civilian workplace and social world. This was understood in terms of generating individuals with an understanding of both military matters (general defence-mindedness), or more specific understanding about the distinctive 
roles of the three armed forces, particularly 'air-mindedness' and 'sea-mindedness. The USUs enabled the armed forces to project a broader view of what the armed forces might do and be within civilian life, beyond the representations prevalent in the media and popular culture.

Recruitment to the armed forces was also an obvious and significant aspect of the value of the units. USUs enabled individuals to make an informed choice about joining the armed forces, to understand how the recruitment process worked and to consider whether an armed forces career was the right choice for them. The value of the USUs also lay in 'de-risking' recruitment for the armed forces by being able to assess an individual's suitability. Recruitment to the Reserves was also understood as benefitting from the existence of USUs in these terms. The USUs also enabled the armed forces to recruit highly educated officers, by definition.

\subsection{Conclusions: the value of the university armed service units to the armed forces}

The individuals interviewed had a range of experience in terms of time spent in command of a unit, and their experiences reflected this. All were positive and enthusiastic about their posting (something evident not only in what was said in the interviews, but also in the way it was said). The COs are key individuals within the USU structure, and although their enthusiasm might be anticipated as a reflection of their professional practice as officers, it is still a point worth making that those in charge of the units have such a high degree of enthusiasm for their work. Some of the COs had little prior knowledge of the units within their service whilst at university or in the earlier stages of their military career (and as one URNU CO said, 'if you had asked me [before becoming CO] I probably wouldn't have seen any benefit in them'), but all were emphatic that there were benefits to students, to universities and to the armed forces from the existence of the USUs. They also clearly enjoyed their specific role in the lives of the students under their command. One of the COs noted, with affection, how:

\footnotetext{
'You're more than a Commanding Officer - you're also a father figure [...] I suggested that part of a pre-requisite to be a Squadron commanding boss was you had to have teenage children, 'cause you knew then how to relate and you knew all the tricks that this lot would get up to and try, the wool they'd try to pull over your eyes.'
}

The key findings from interviews with COs are as follows (and we note again that we have not included here repetition of points made by students and graduates, all of which were identified by the COs, unprompted, during the interviews). 
In terms of the nature of the USU-university relationship, the diversity of types of university from which USUs draw their students and with which they engage, and in turn the range of students attracted to USUs, is a notable feature. As a mechanism for facilitating this relationship, MECs vary in terms of their levels of activity and the utility of those activities to COs. Specific individuals, including but not limited to MEC Chairs, can be invaluable to COs in terms of developing working relationships with specific universities. CO perceptions of the attitudes of Student Unions towards the USUs show a range of responses, and COs are very aware of their role in negotiating these student-armed forces relationships. The informal and ad-hoc relationships that COs may develop with individuals or departments within universities are also an element of the USU-military relationship.

In terms of the value of the USUs to universities, this was thought to lie with the value that units were able to bring to students through the range of USU activities. USUs were seen as being significant in the development of individual students, and as a group with an enhanced skills set; this is turn was thought to reflect back positively on to universities, particularly when those students graduated and went into employment. We perceived that some COs were of the view that universities, both as individual institutions and as the higher education sector, could potentially benefit to a greater degree from the relationship with the armed forces articulated through the USUs, and that universities could potentially reap greater rewards from that relationship than they might do at present.

In terms of the value to the USUs and the armed forces of the relationship with universities, this was seen to be manifest in the recruitment of good students into the units. The association that units had with a particular university might be beneficial in terms of the public image of a particular unit. The ability for the armed forces to potentially recruit good candidates for officer training, either for the Regulars or the Reserves, because of the relationship via USUs was recognised. There was value for the armed forces too in the enhanced visibility for those forces within the universities, and this was notable at a time of reduced public awareness of military forces.

Assessments by COs of the overall value of the USUs emphasised these points about the value to individual students of the experience of the USUs and the value to the armed forces of the existence of the units.

There are two final points to make in conclusion. The first concerns the differences between universities and armed forces in terms of organisational character and culture, levels of central direction versus autonomy, the locus of power for central direction in each institution, the function of chains of command and hierarchies (particularly in terms of the flow of information up and down hierarchical and across horizontal communication chains) and the ways in which both organisations can and do initiate change and react to external changes. Added to this is the relative size of the units compared to the size of the universities with which they engage. Given these factors, it is probably not 
surprising that the USU-university relationship can present challenges, particularly for individuals put in command of a unit for a limited period of time and facing a very steep learning curve.

The second point concerns the question of the use of scarce financial resources in maintaining the units. It is notable that in the interviews with COs, despite having the opportunity to raise the point, there was very little commentary from COs about the financial costs and quantifiable benefits of the USUs. Where this was mentioned, it was raised as question of possible conflicts over the use of scarce resources within the armed forces, particularly within the context of budgetary cuts. The fact that the question of financial resources was not highlighted is not proof that this issue is far from the minds of COs. Nonetheless, we suggest that it is indicative of the attitudes of the COs interviewed that they were so clearly able to articulate wide-ranging and detailed arguments about the value (and otherwise) of the USUs to the armed forces and to the universities, without reducing the issue to a question of budgets and balance sheets. 